\title{
Capturing the Essence: Development of Regulatory Concept Maps
}

\section{Maryann Alexander, PhD, RN, FAAN}

$\mathrm{S}$

tep Two of the Regulation 2030 study is described here and concerns the gathering of experts and the development of concept re possibilities (both positive and negative). Interpreting these trends for the future and their implications was relegated to experts from around the world. These experts projected what needs to be in place to deliver the trends and identified the impact these trends may have on regulation and the associated health care system.

\section{Regulation 2030 Summit}

Regulation 2030 was a 2-day summit that brought regulators and health care leaders from across the United States and around the world to Chicago to envision the future of regulation. The attendees were carefully selected for their knowledge of nursing, regulation, and health care; their diversity; and their leadership. Eighty individuals attended the summit, and represented 8 countries, 17 U.S. states, the District of Columbia, and 2 U.S. territories.

Participants were assigned to eight work groups. Table assignments were made to ensure there were varying expertise and viewpoints in each of the work groups, providing a balanced perspective as attendees familiarized themselves with the 25 emergent trends and became accustomed to the format of the later exercises. After the first few segments, attendees were free to select new work groups in order to explore different subject matter and collaborate synergistically with a new group of people, generating continually fresh ideas. Although an attendee might have been a subject matter expert in a particular category, the attendees were encouraged to weigh in on trends that traversed a diverse selection of categories throughout the summit.

\section{Emergent Trends}

The 25 emergent trends were introduced by David Benton. Dr. Benton had done the original analysis and produced the emergent trends by performing a bibliometric analysis of peer-reviewed literature related to professional self-regulation and occupational licensure as described in Step One. Using this methodology, he identified 25 emergent trends that accompany seven categories of regulation, including governance, purposes and processes, licensees/registrants, workforce, education, fitness for practice, and technology and information. Participants were provided reading materials in advance, including a list of the 25 emergent trends, to help them prepare for the summit. These trends, which provided insight and a pathway for the future of regulation, were central to the meeting.

After this introduction, the participants were asked to examine and discuss the emergent trends in their small work groups. It was important that all participants understood the meaning of each emergent trend. Participants had the opportunity to ask questions, and clarification was provided. Participants were also asked to identify trends that may be missing. A leader of each group then summarized key points from their discussion of the trends and reported these to the group in its entirety. While there was much discussion and many suggestions for additional trends, upon examination, all of the suggestions were able to be identified as belonging to one of the already existing 25 emergent trends. Once everyone had a clear understanding of the 25 trends, the process of concept mapping was introduced. 


\section{Concept Mapping}

Concept mapping is a method of brainstorming and structuring ideas and relationships around a general theme (Novak \& Cañas, 2014). The small work groups were each assigned an emergent trend that was printed in the center of a large poster board. Participants were given notepaper and colored pens, and were instructed to expand on the trend by brainstorming ways in which the trend might continue to develop over the coming years, including possible ultimate outcomes of both a positive and negative nature. Participants explained their thoughts, wrote them down, and added them to the board, often generating a wave of secondary ideas from other participants.

The ideas the participants were asked to generate fell into two broad categories, defined as follows:

1. Requirements: systems, processes, or technologies that must be in place to make the theme (or its deliverables) a reality

2. Deliverables: changes to the state of nursing that may result from the emergent trend, and may be perceived of as positive or negative.

Participants then used arrows to connect the concept they had just placed on the board to the trend itself, as well as to any of the other added concepts to which their idea might be related. A blue arrow indicated that a concept was a deliverable of the overarching trend; a red arrow indicated that the concept was a requirement that needed to be in place for the overarching trend (or one of its deliverables) to come about.

By placing their notes around the emergent trend in the center of the board, and connecting the various ideas to the trend and other concepts with arrows, the teams developed a concept map. They then had an opportunity to review and refine their concepts and thoughts as further discussion ensued and more ideas were generated. This exercise was carried out three times in three separate conceptmapping sessions. During each mapping session, each of eight work groups focused on expanding upon one of the emergent trends. At the end of the day, the completed maps were mounted on a wall. Participants were allotted time to view the maps made by the other participants and add additional ideas to the maps, if any were missing.

\section{Evaluating the Maps}

Day 2 of the summit began with a review of day 1, which was followed by participants walking around and once again viewing the now-complete concept maps. They were asked to evaluate the maps in two different ways. First, they were asked to analyze each individual map for higher-order trends: groups of interrelated concepts that, taken together, made a larger statement about the direction a trend would impose upon the future of regulation, or the infrastructure that would need to be in place to bring it about. Second, the participants were asked to note any common elements (requirements and/or deliverables) that recurred on multiple maps that they considered essential to the future of nursing regulation. Participants were asked to prioritize and determine what was most important in driving the profession toward new paradigms in nursing regulation. They returned to their small groups and discussed the overarching trends that appeared to be emerging. The groups were also asked to identify the top five requirements needed for the future along with the five most-important deliverables. Each group reported what they felt were most essential to the future of nursing regulation.

Discussion occurred around the question: What elements (requirements and/or deliverables) would we put in a plan for the future? Some emergent trends identified were the need for transparency, use of evidence to drive public protection, being proactive rather than reactive, the need for maximizing technology and sharing of data, security of data, engagement of the public (including licensees and employers), having an interprofessional focus and teamwork, the need for creating standards, flexibility, and adequacy and strategic use of financial resources, with an ethical lens around all of the themes and challenges.

\section{Standardization}

The standardization of board processes, and subsequent improved efficiency, was identified as an element or requirement in many of the emergent trends. From creating standardized processes internally to harmonizing processes among several boards, standardization was predicted to play a role in education, fitness to practice, and technology, in ways such as creating streamlined decision-making or disciplinary processes, establishing educational benchmarks, creating guidelines for performance assessment, and discussing the dataset that regulatory bodies maintain for licensees and the manner in which it is stored and accessed.

\section{Data}

On a related note, many of the concept maps contained emergent trends related to the optimal leveraging of data. Data, captured and accessed through next-generation processes, were seen as a source of untapped potential for bringing about change in a variety of areas. In the realms of governance and processes, evidence would drive change in decision making and standards of practice. In education, participants imagined data not only fueling better program outcomes but also optimizing clinical experiences and providing metrics for continued competence. Additionally, participants imagined the ability of future data systems to better assist in systems and workforce planning. Hand in hand with advanced data collection, many of the maps identified a strong technical infrastructure to be essential as the trends moved forward, making possible advancements in board processes and tracking licensees/registrants' fitness to practice. Participants also imagined a future technical infrastructure that allowed the transjurisdictional registration of nurses, which in turn 
would create a globally mobile workforce that had the capacity to ensure interjurisdictional public safety. The impact of this global mobility also left its mark on maps related to workforce planning, board processes, and fitness to practice.

\section{Collaboration}

The single trend that appeared in concept maps across all categories was collaboration. Participants imagined that collaboration of regulatory bodies globally would transform governance of professions. Board processes would be transformed by collaboration not only geographically but also across disciplines. Multidisciplinary collaboration would also impact the licensees/registrants themselves and the manner in which they are educated; global collaboration, the participants inferred, would be a requisite in managing the workforce and fitness-to-practice challenges in the coming years. With ripple effects on nearly every map, participants seemed to identify collaboration as a key to the future.

A final trend that appeared on many maps across multiple categories acknowledged the combined effect of streamlined technology, more effective assessment of fitness to practice, evidence-based processes, transparent and accountable governance, and a competent, collaborative, and mobile workforce - that is, an emergent trend of improved safety and quality and increased protection of the public.

\section{Prioritizing Key Requirements and Deliverables}

Each of the eight groups then identified and reported on their top five requirements and deliverables for regulation in the year 2030.

\section{Key requirements}

The key requirements identified included:

- creation of common definitions and core competencies for licensees and for a global workforce

- legislative changes regarding authority required for boards to work collaboratively and cooperatively

- creation of rules, regulation, and statutes with diversity in mind

- flexibility to respond to changing needs

- collaboration among boards, government, stakeholders, disciplines, educators, and employers

- standardization of education, scopes of practice, and rules, including cultural competency and ethics, with focus on outcomes and public engagement

- data systems that enable information sharing globally, with standardized data elements, systems, and measures

- global collaboration among all nursing regulators, stakeholders, professionals, the public, and interdisciplinary education groups

- role clarity

- redefinition of the role and purpose of regulation, with empowerment of consumers

- use of technology to enhance the licensure processes

- adequate funding, with resources

- creation of an evidence base and research so regulation is based on evidence and data

- strong leaders and mentors

- transparency

- use of ethics as the guiding principle for regulatory work.

\section{Key deliverables}

Key deliverables included:

- need for good data systems, for data that are secure, and for global data systems to enable information sharing

- transparency of board functions, qualifications, communication among stakeholders: public involvement, with an increase in public trust

- harmonization so there is knowledge and understanding of what boards do

- public trust of regulation and regulators

- increased workforce mobility

- interjurisdictional trust, international registers and registration, with similar competencies, trust, and databases

- more-enabling legislative framework, with less control by legislatures of board policies

- uniform accreditation standards

- increased efficiency

- globalization of health care professionals, with a shared vision and a global perspective

- diverse workforce and faculty that reflect the patients

- technology that can achieve standardization

- evidence-based decision making, rather than decision making based on emotions. 


\section{Finalizing the Maps}

In the days following the summit, discussion leaders from the eight small work groups each reviewed the completed maps on which they had led a discussion. Map notes (or the maps themselves) were reorganized and consolidated to provide a clear and accurate depiction of each group's discussion and their thoughts for the future.

The efforts put forth by the summit participants and small-group leaders established the foundation for the next groundbreaking step in this process: to analyze the actual content of the 25 concept maps. The following section discusses Step Three-Analysis and priorities: Developing a modern, effective regulatory framework.

\section{Regulation 2030: Concept Maps}

Using Visio software, the 25 completed concept maps were transcribed into a digital format. The software permitted map notes to be moved around to better cluster ideas and visualize connections. Once maps had been reformatted in this manner, the small-group leaders were asked to identify higher-order themes by drawing a green box around clusters of notes. The higher-order theme that best captured the discussion was notated on the map. This final step marked the completion of the concept maps. 


\section{CONCEPT MAP 1}

\section{Governance > Nature Of Regulator > Performance-Managed Bodies With Independent Oversight}

This concept map explores the nature of the regulator theme in relation to governance and its emergent trend, performance-managed bodies with independent oversight.

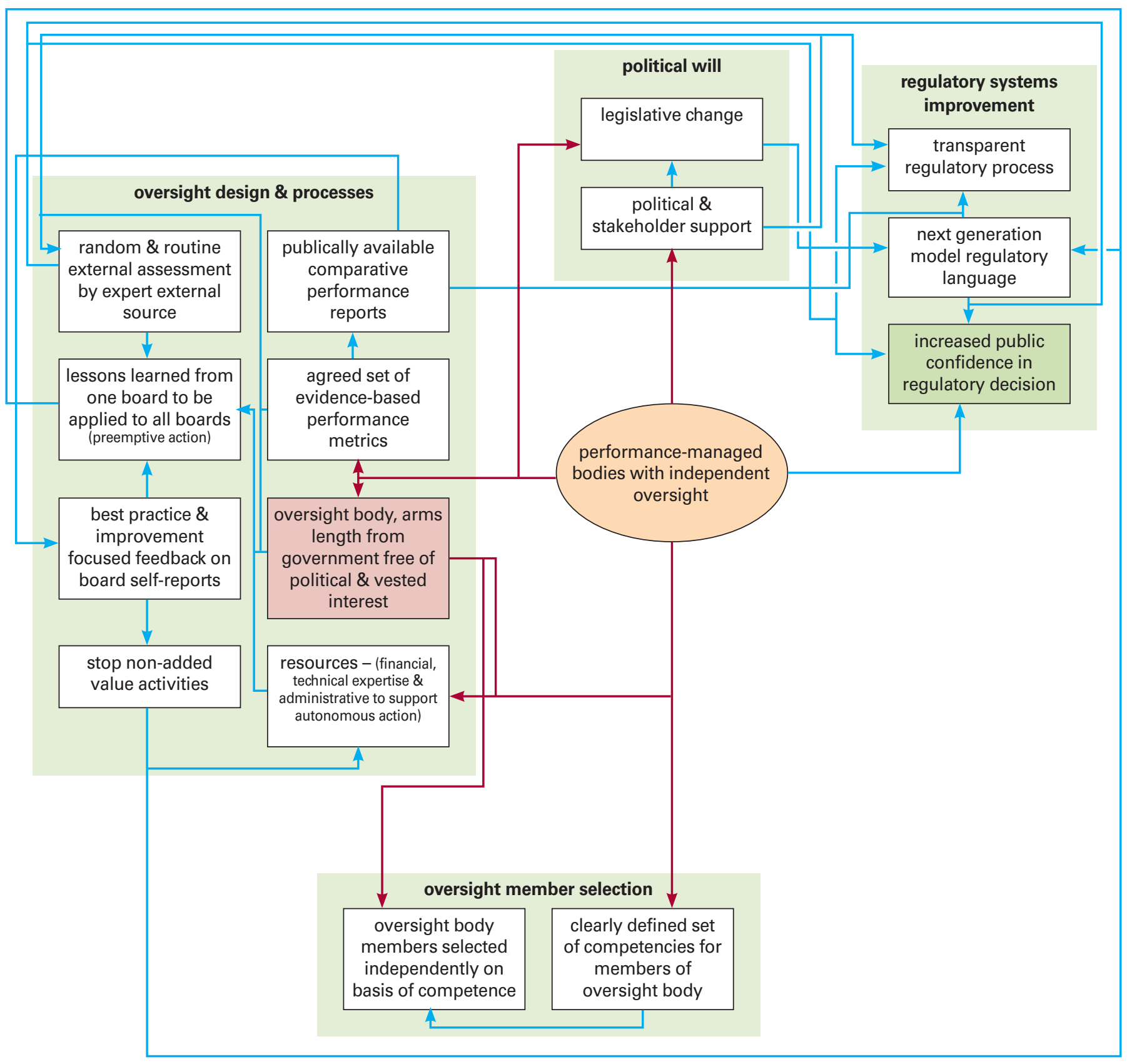




\section{CONCEPT MAP 2}

\section{Governance > Character Of The Board > Governance Focused With Increased Public Accountability}

The concept map explores the character of the board theme in relation to governance and its emergent trend, governance-focused with increased public accountability.

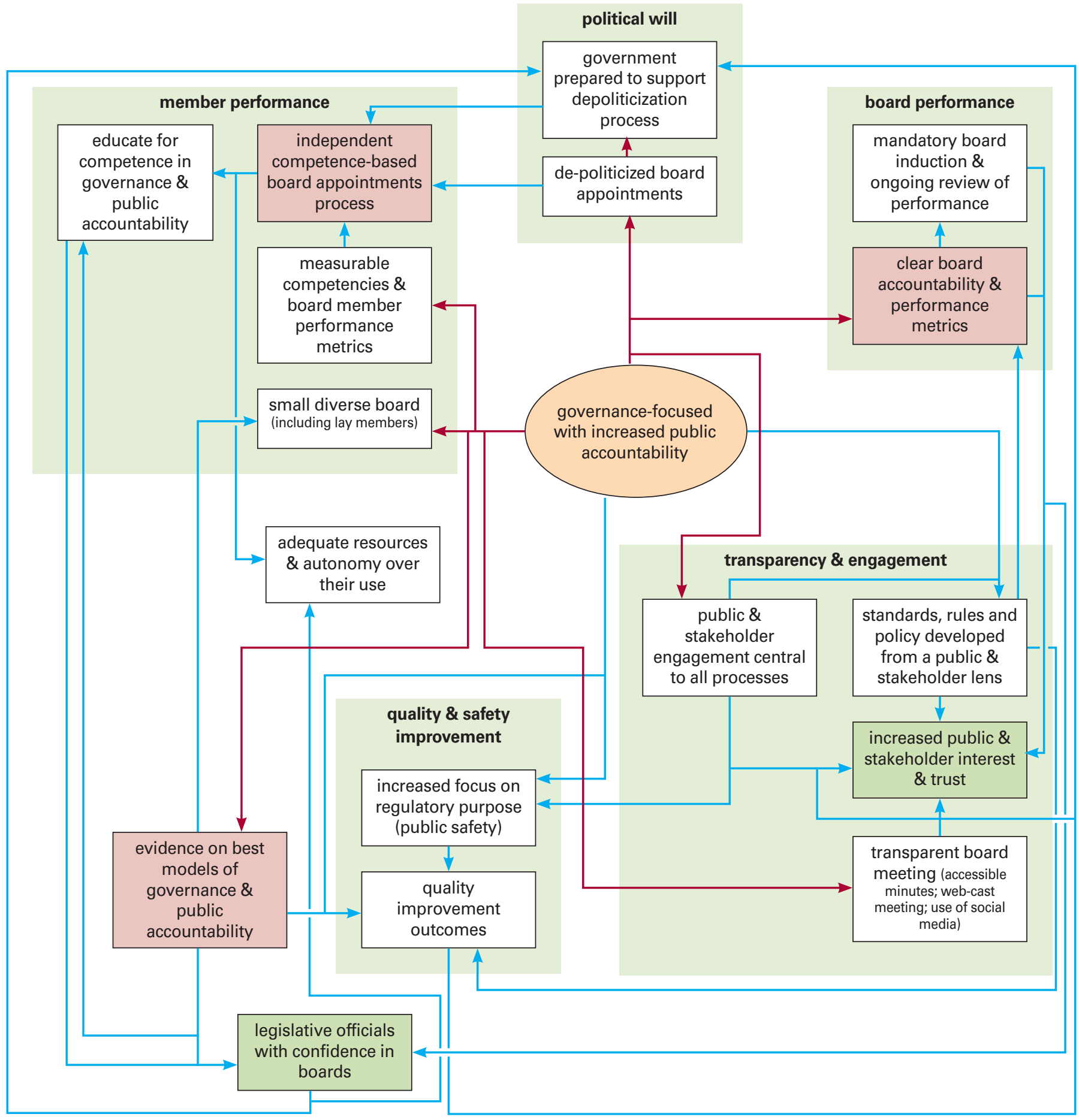




\section{CONCEPT MAP 3}

\section{Governance > Members Of The Regulatory Board > Increasingly Competence-Assessed And Appointed Through Impartial Process}

This concept explores the members of the regulatory board theme in relation to governance and its emergent trend, increasingly competence-assessed and appointed through impartial process.

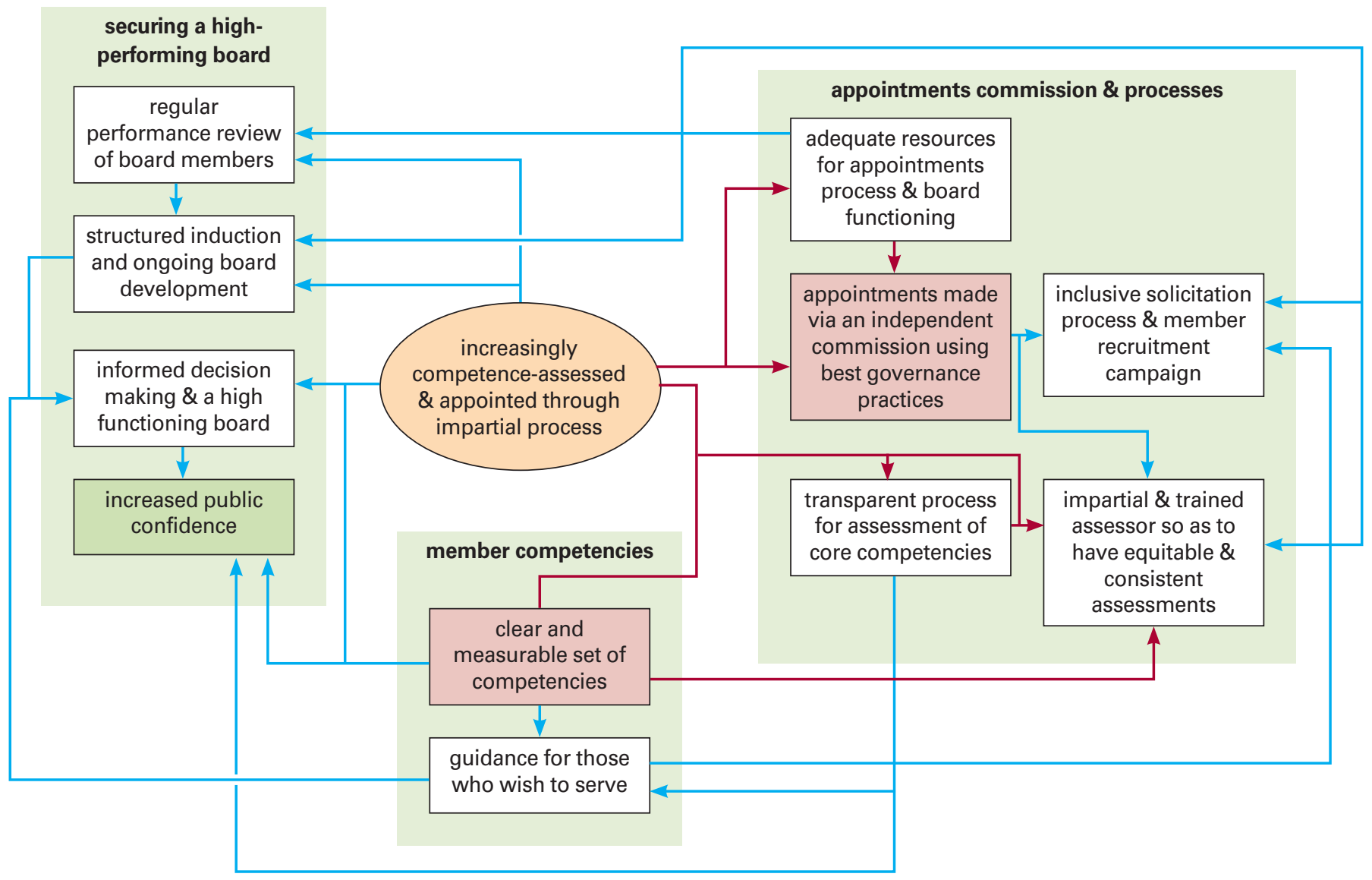




\section{CONCEPT MAP 4}

\section{Governance $>$ Accountability $>$ Mixed Models of Accountability}

This concept map explores the accountability theme in relation to governance and its emergent trend, mixed models of accountability.

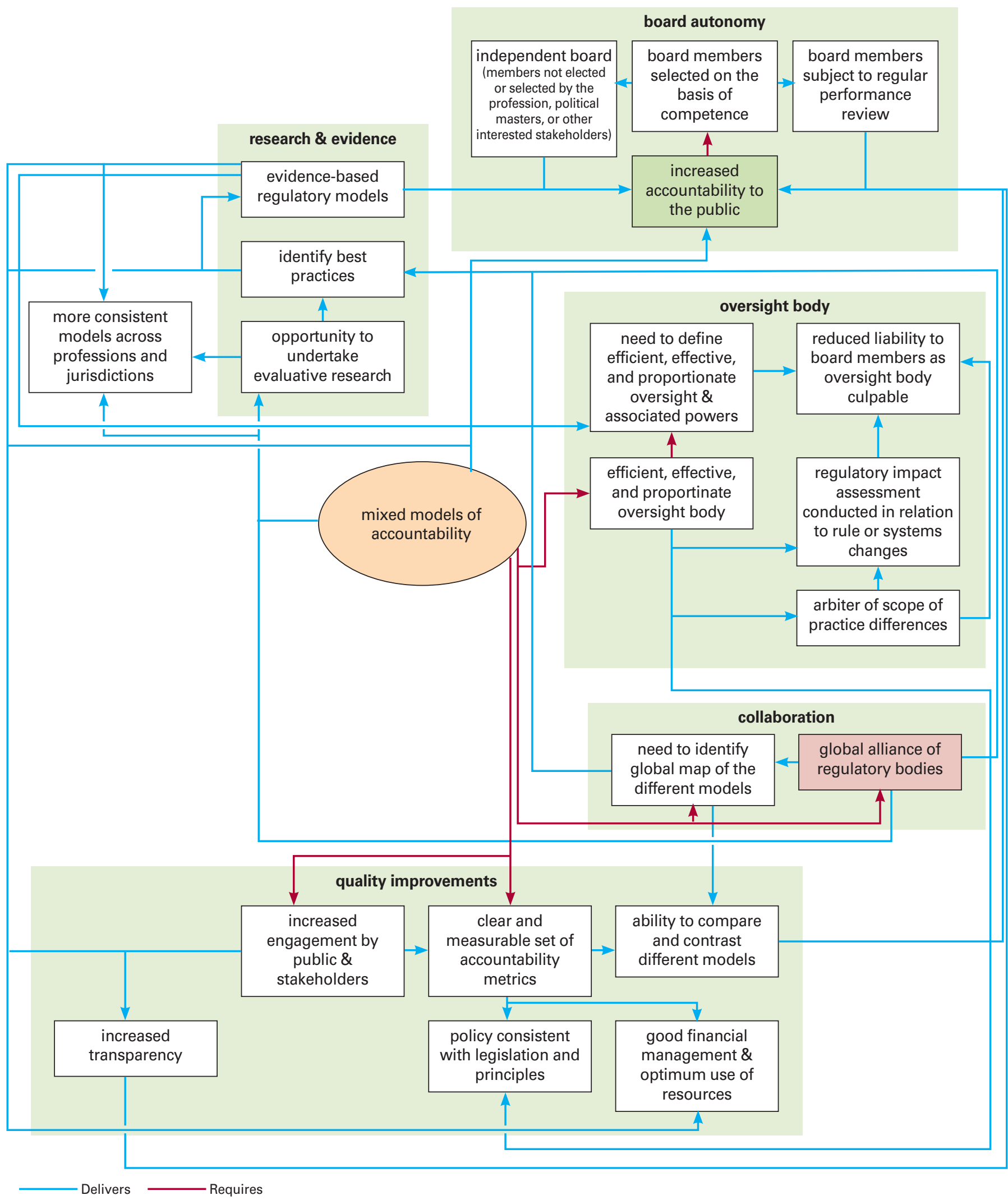




\section{CONCEPT MAP 5}

\section{Purpose and Processes > Decision Making > Principle-Based Decision Making with Rationales for Judgments}

This concept map explores decision making purpose theme in relation to purpose and processes and its emergent trend, principlebased decision making with rationales for judgments.

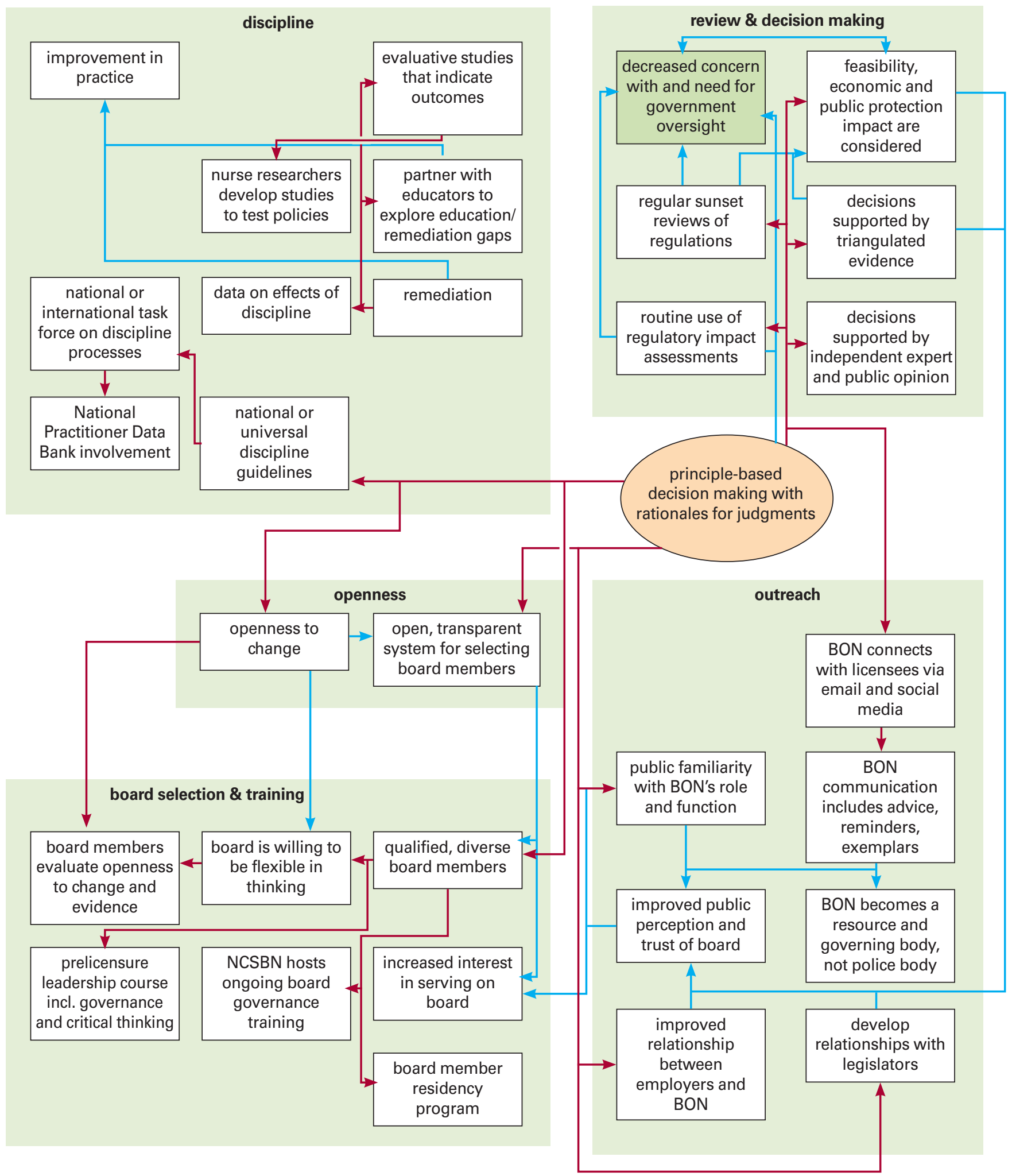




\section{CONCEPT MAP 6}

\section{Purpose and Processes > Process of Regulation > Evidence-Based Processes}

This concept map explores process of regulation theme in relation to purpose and processes and its emergent trend, evidence-based processes.

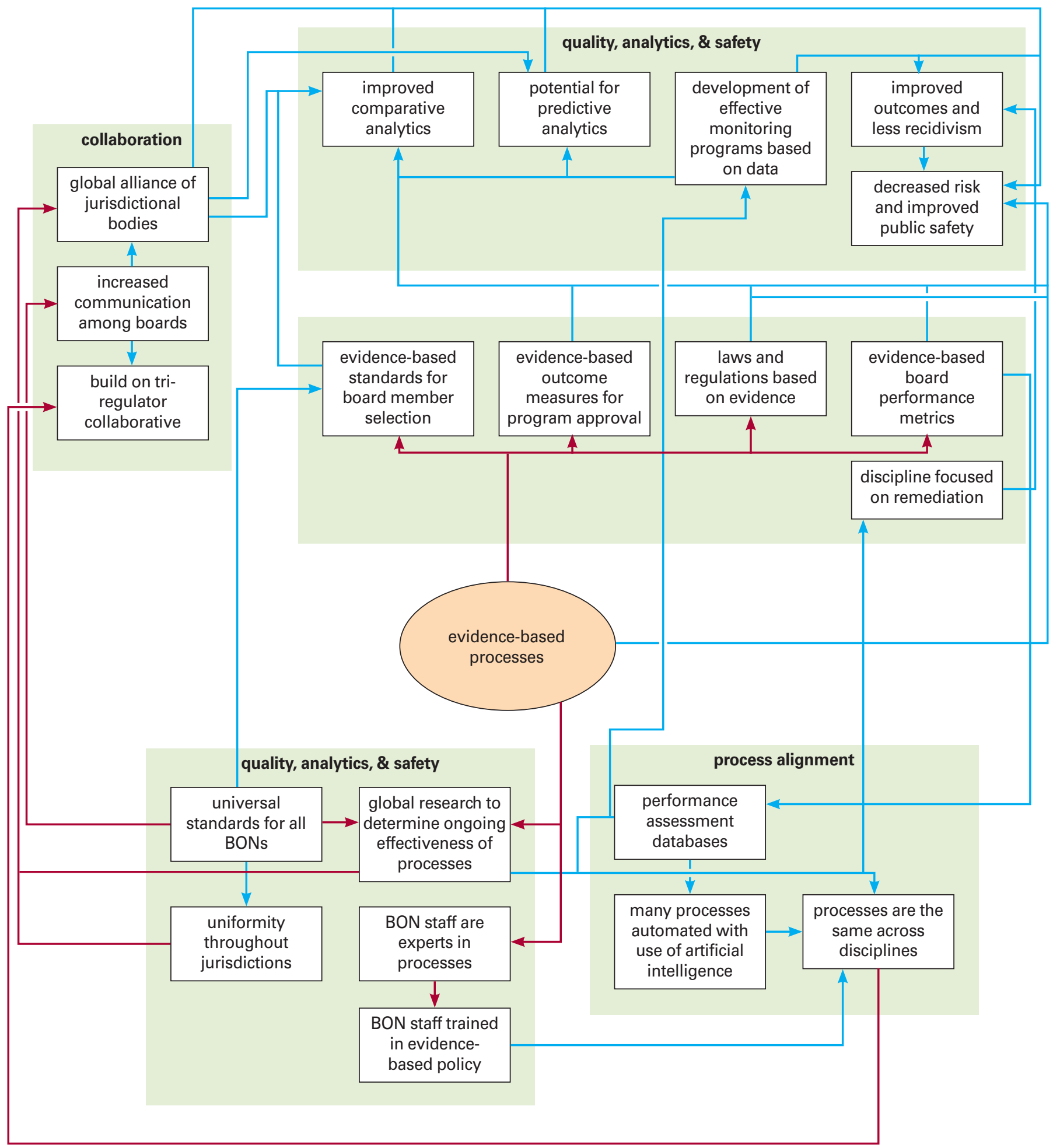

Delivers Requires 


\section{CONCEPT MAP 7}

\section{Purpose and Processes > Protecting the Public > Complex and Dynamic System of Coordinated Players}

This concept map explores protecting the public theme in relation to purpose and processes and its emergent trend, complex and dynamic system of coordinated players.

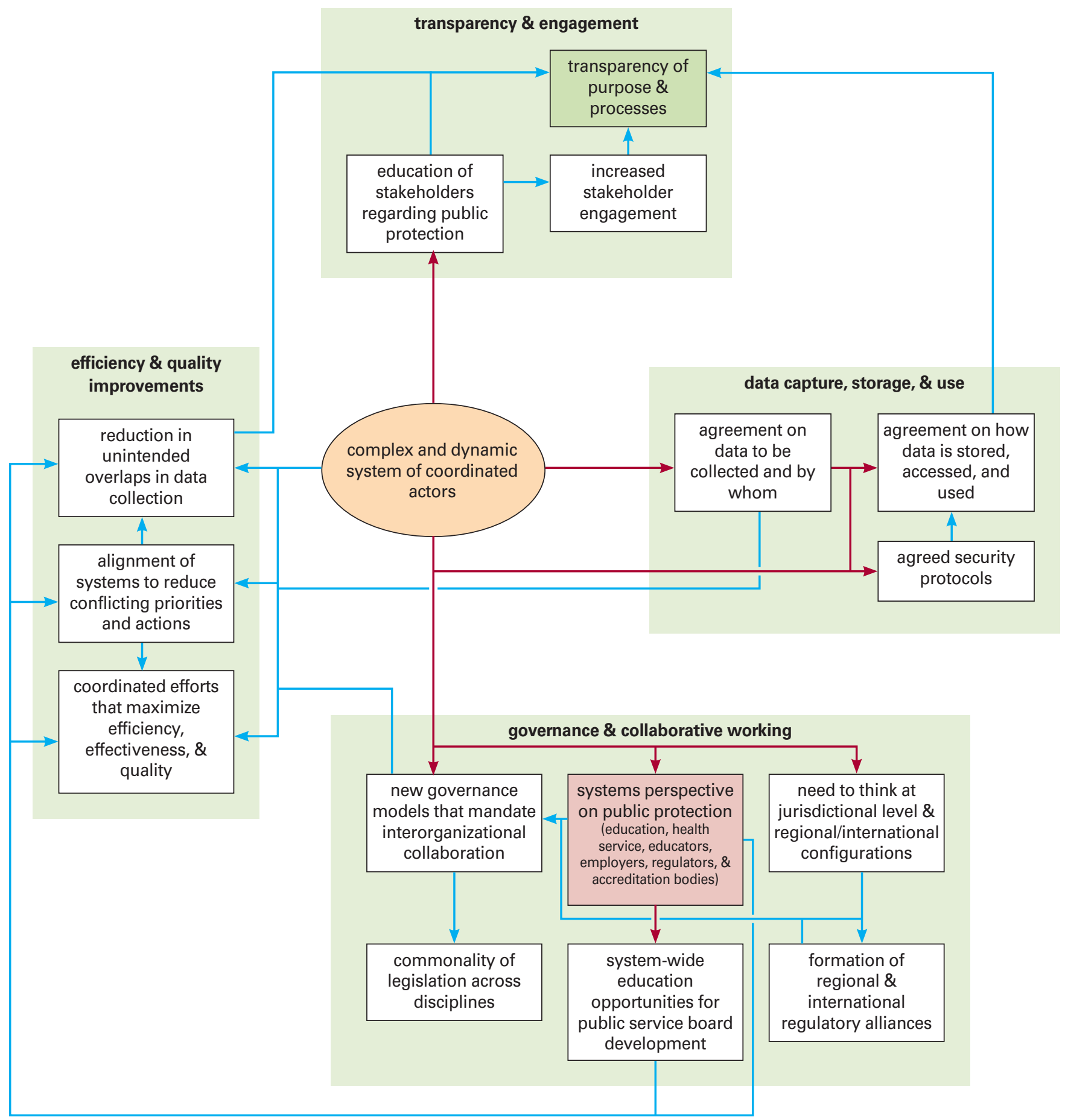




\section{CONCEPT MAP 8}

Purpose and Processes > Organizational Drive > Leaders and Scholars Focused on Contemporary Solutions

This concept map explores the organizational drive theme in relation to purposes and processes and its emergent trend, leaders and scholars focused on contemporary solutions.

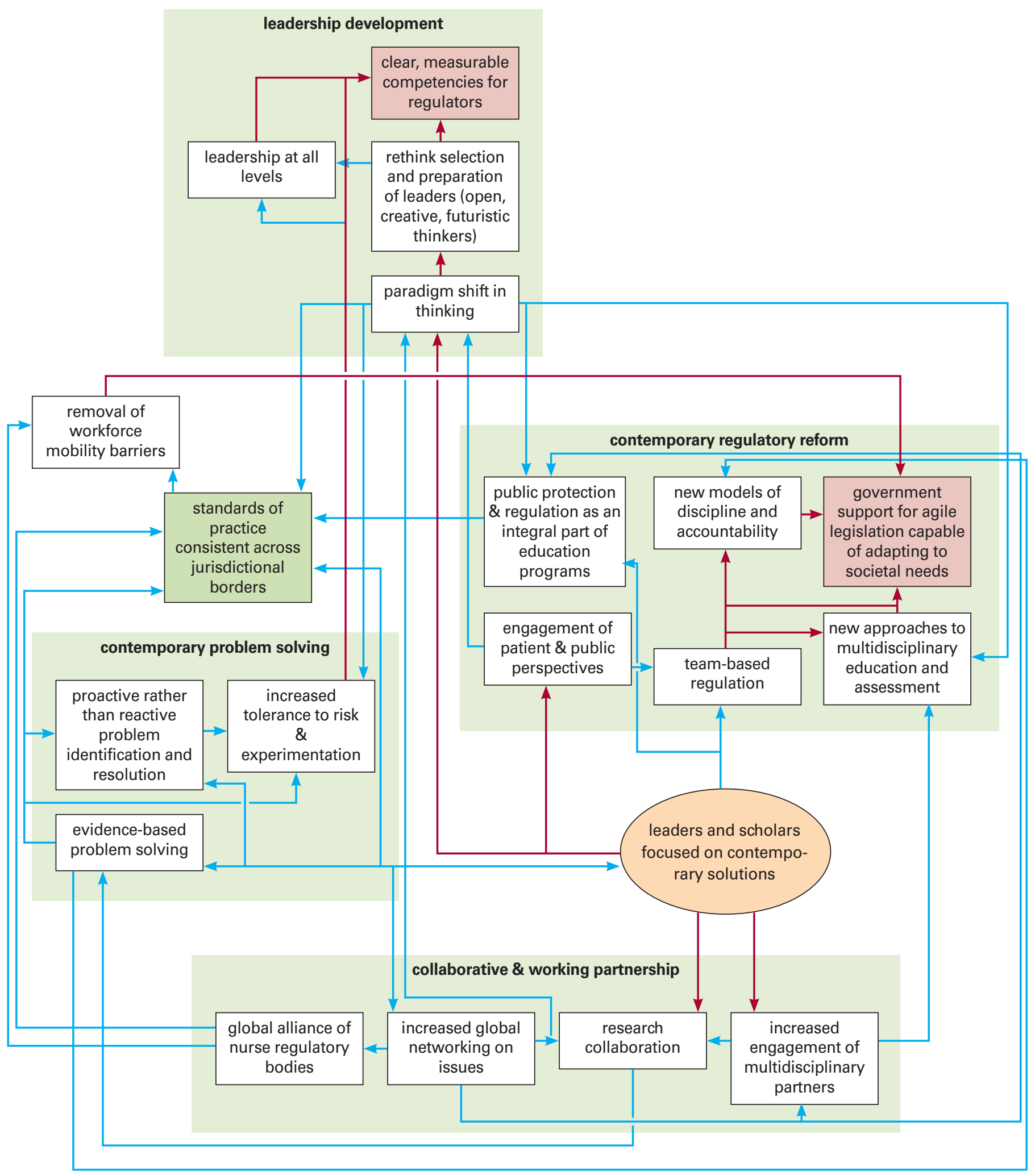

Delivers 


\section{CONCEPT MAP 9}

\section{Licensees/Registrants > Those Regulated > Team-Based Regulation}

This concept explores the those regulated theme in relation to licensees/registrants and its emergent trend, team-based regulation.

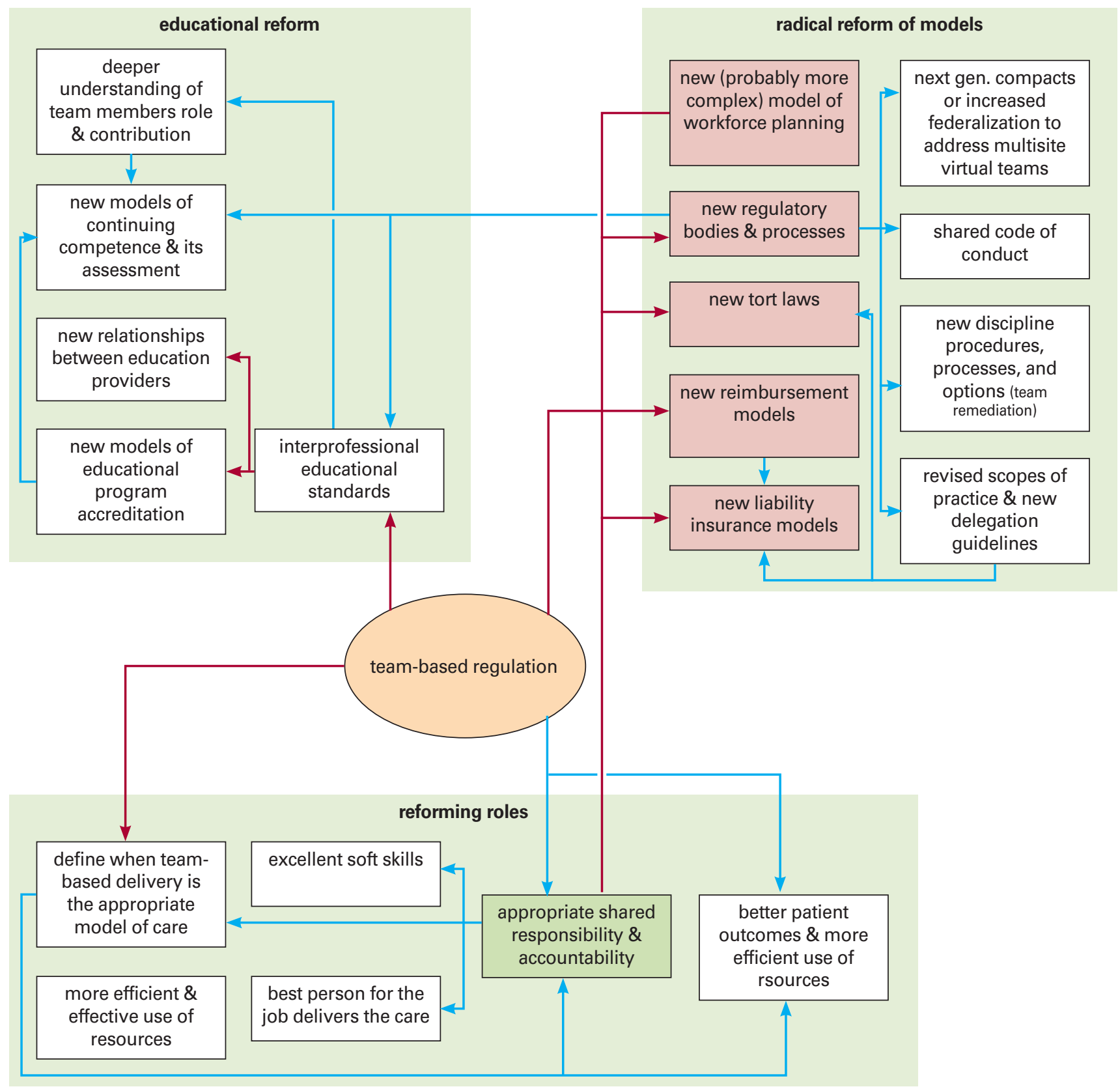




\section{CONCEPT MAP 10}

\section{Licensees/Registrants > The Register > Transjurisdictional Register of the Competent and Privileged}

This concept map explores the register theme in relation to licensees/registrants and its emergent trend, transjurisdictional register of the competent.

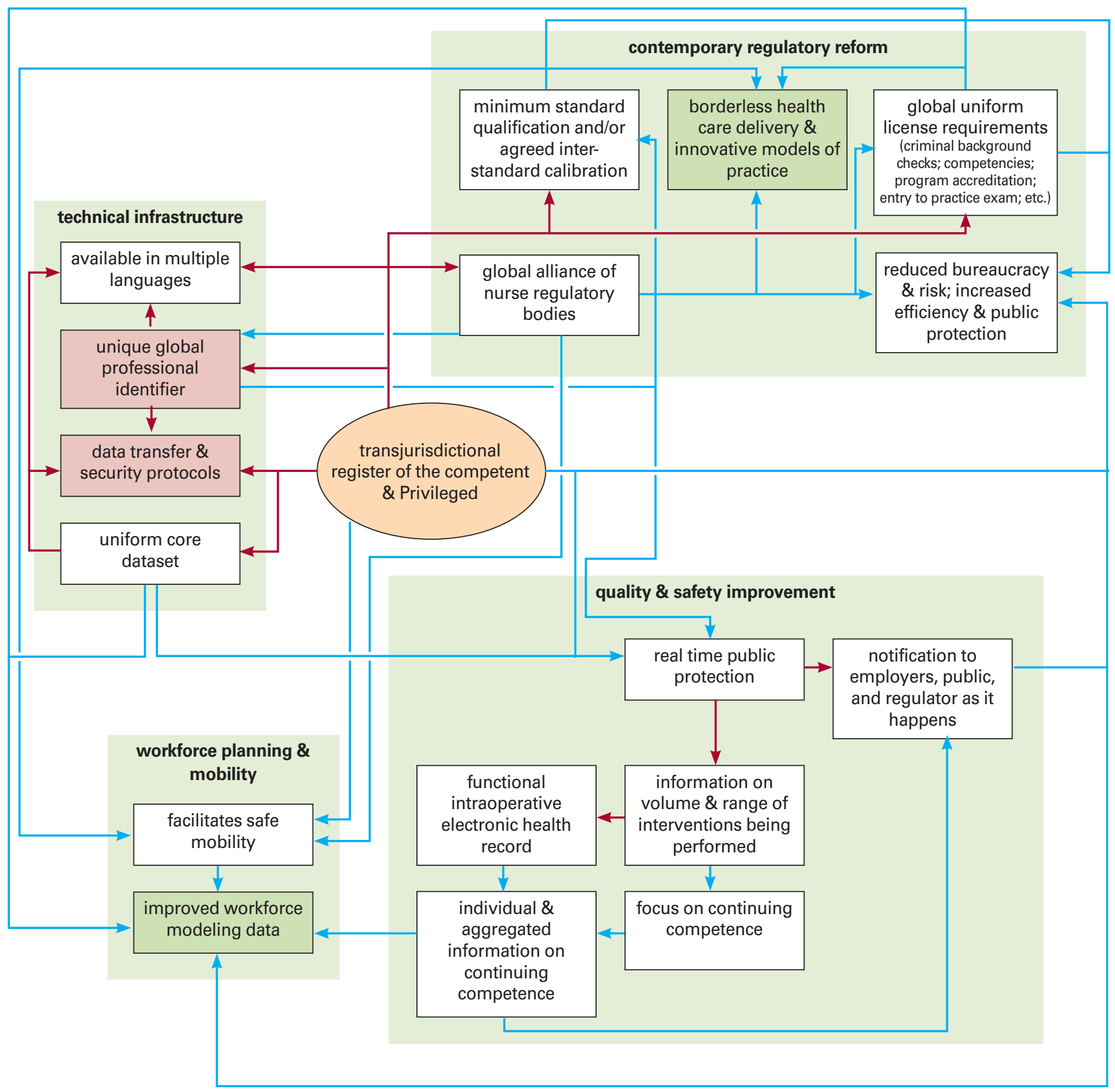




\section{CONCEPT MAP 11}

\section{Licensees/Registrant > Types of Practitioners > Shared Competence with a Continuum and Team-Based Models of Practice}

This concept map explores the types of practitioners theme in relation to Licensees/Registrants and its emergent trend, shared competence with a continuum and team based-models of practice.

collaboration, efficiency, \& effectiveness

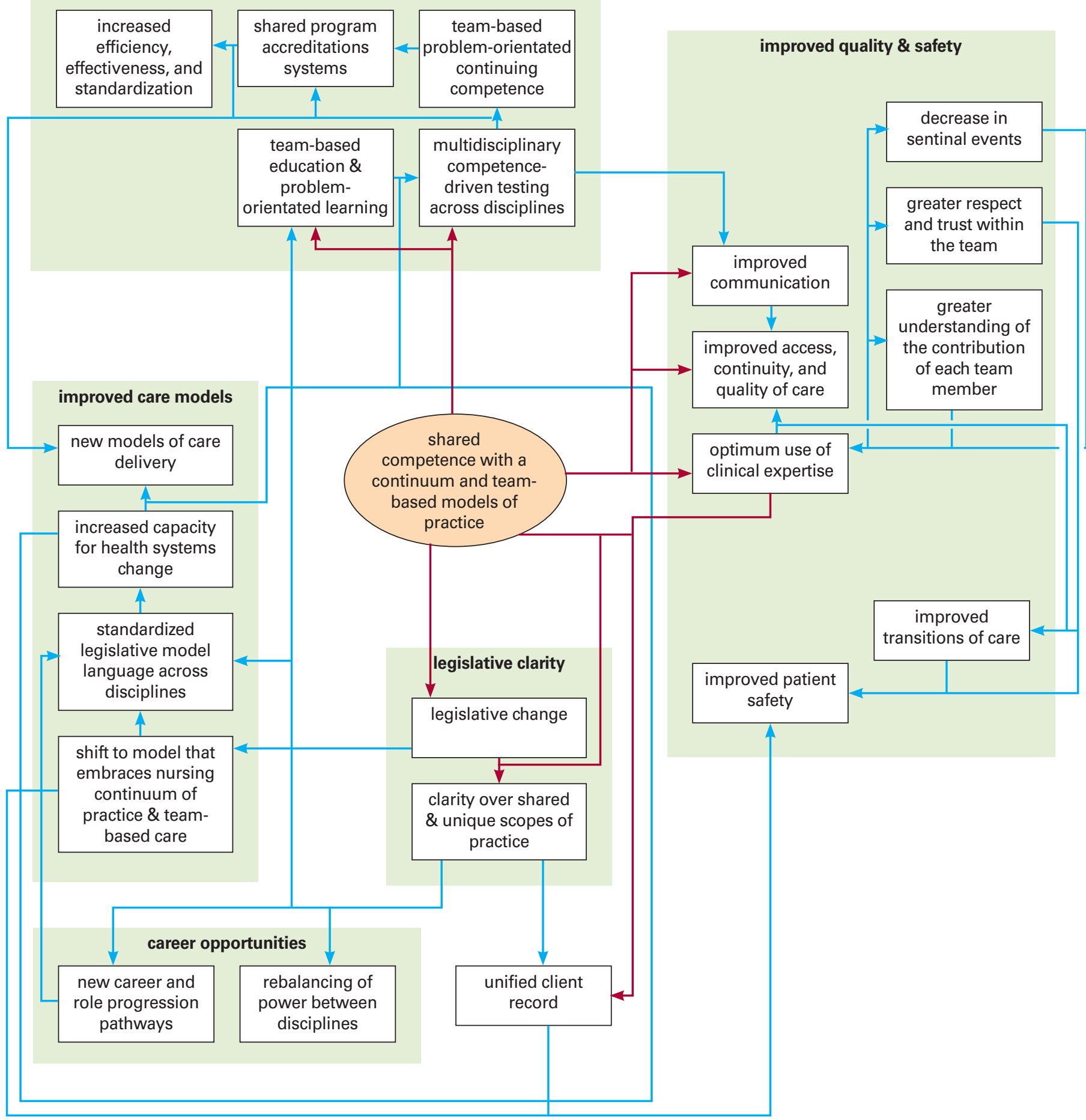




\section{CONCEPT MAP 12}

\section{Workforce $>$ Nature of the Workforce $>$ Multigenerational Careers}

This concept map explores the nature of the workforce in relation to the workforce category and its emergent trend, multigenerational careers.

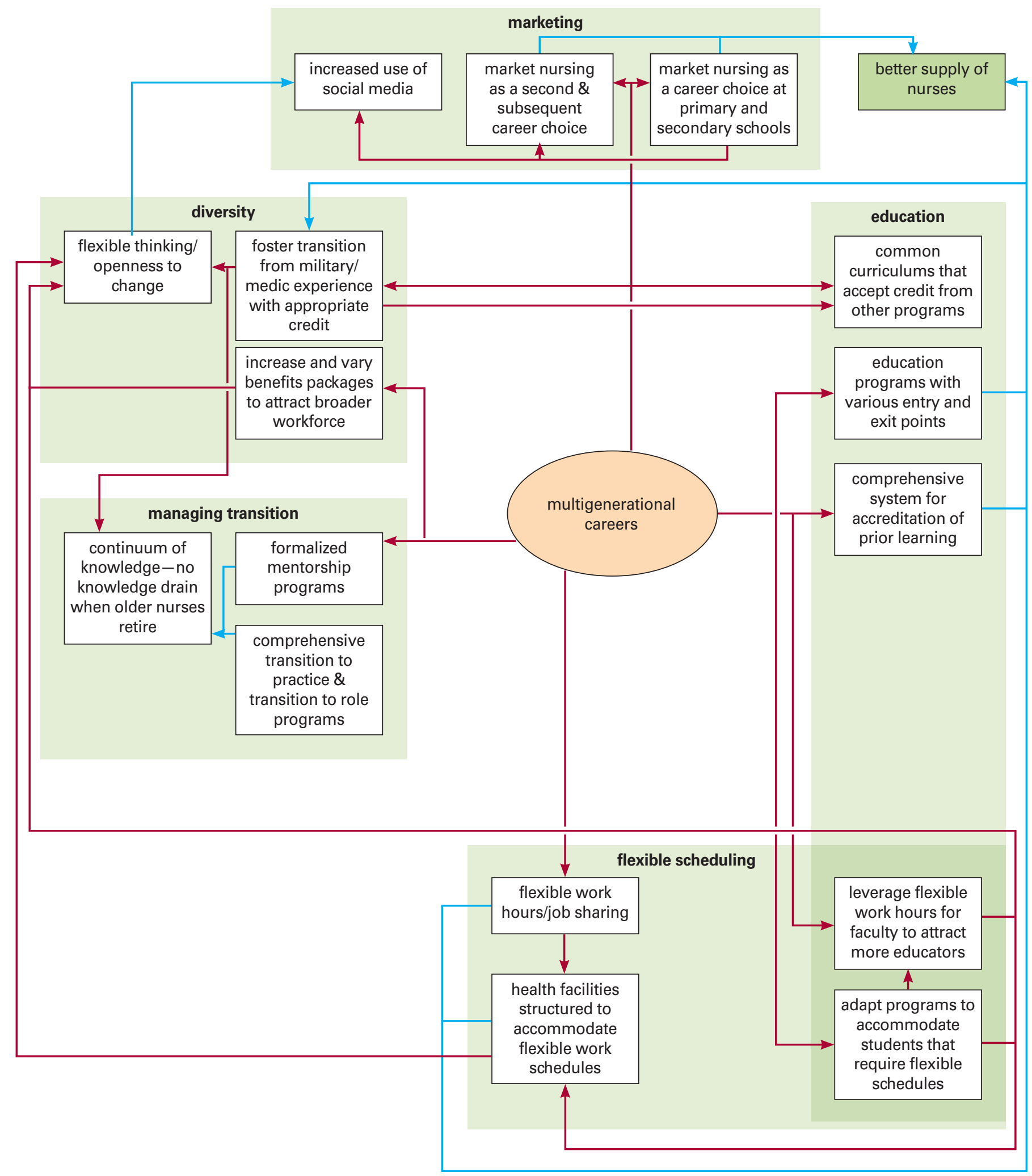




\section{CONCEPT MAP 13}

\section{Workforce > Workforce and Educational Planning > Systems and Regional Economy Planning}

This concept map explores the workforce and education theme in relation to workforce and its emergent trend, systems and regional economy planning.

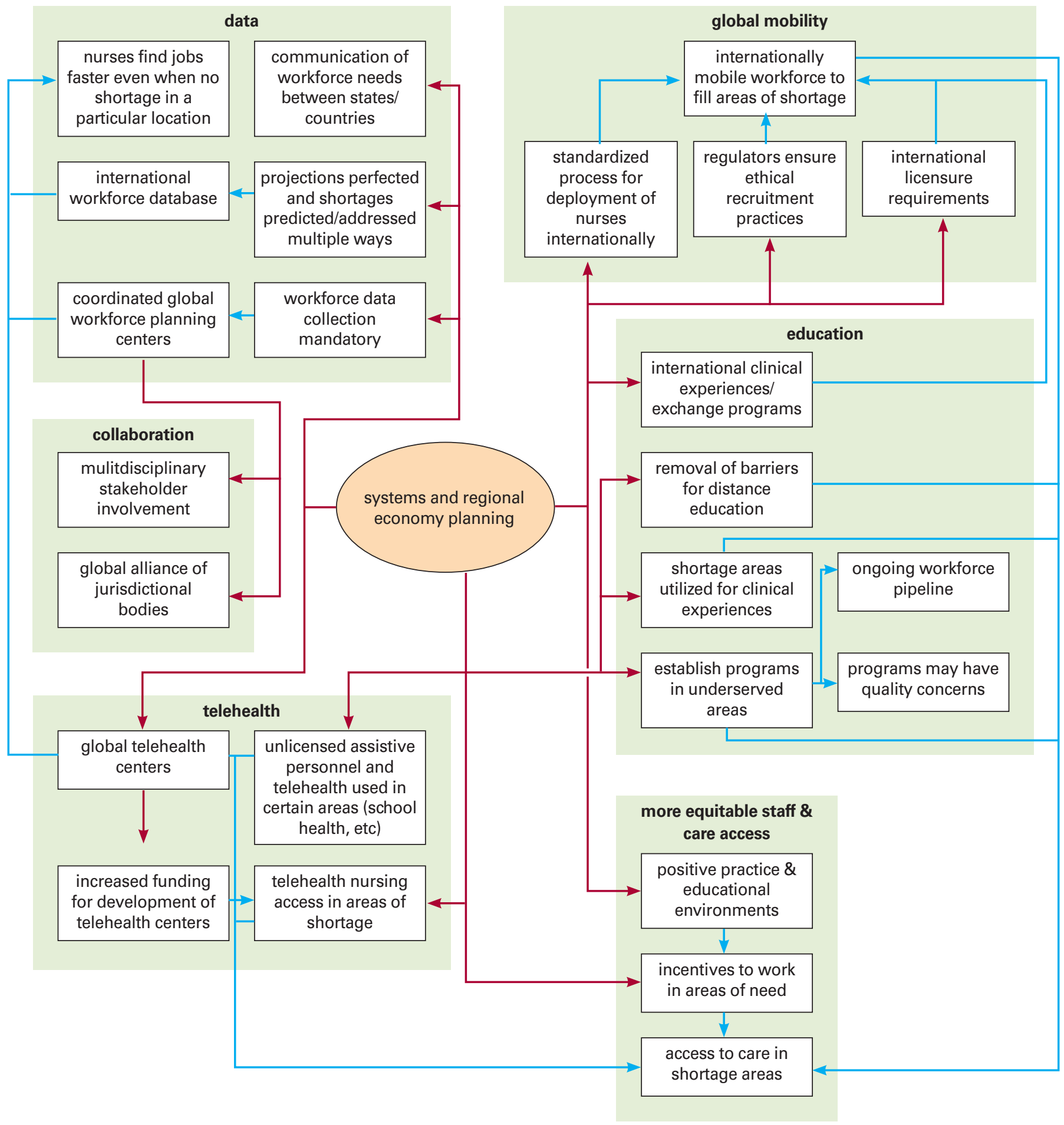




\section{CONCEPT MAP 14}

\section{Education > Setting Standards > Higher Level Competencies Relating to Judgment and Decision Making}

This concept map explores the setting standards theme in relation to education and its emergent trend, higher level-competencies relating to judgment and decision making.

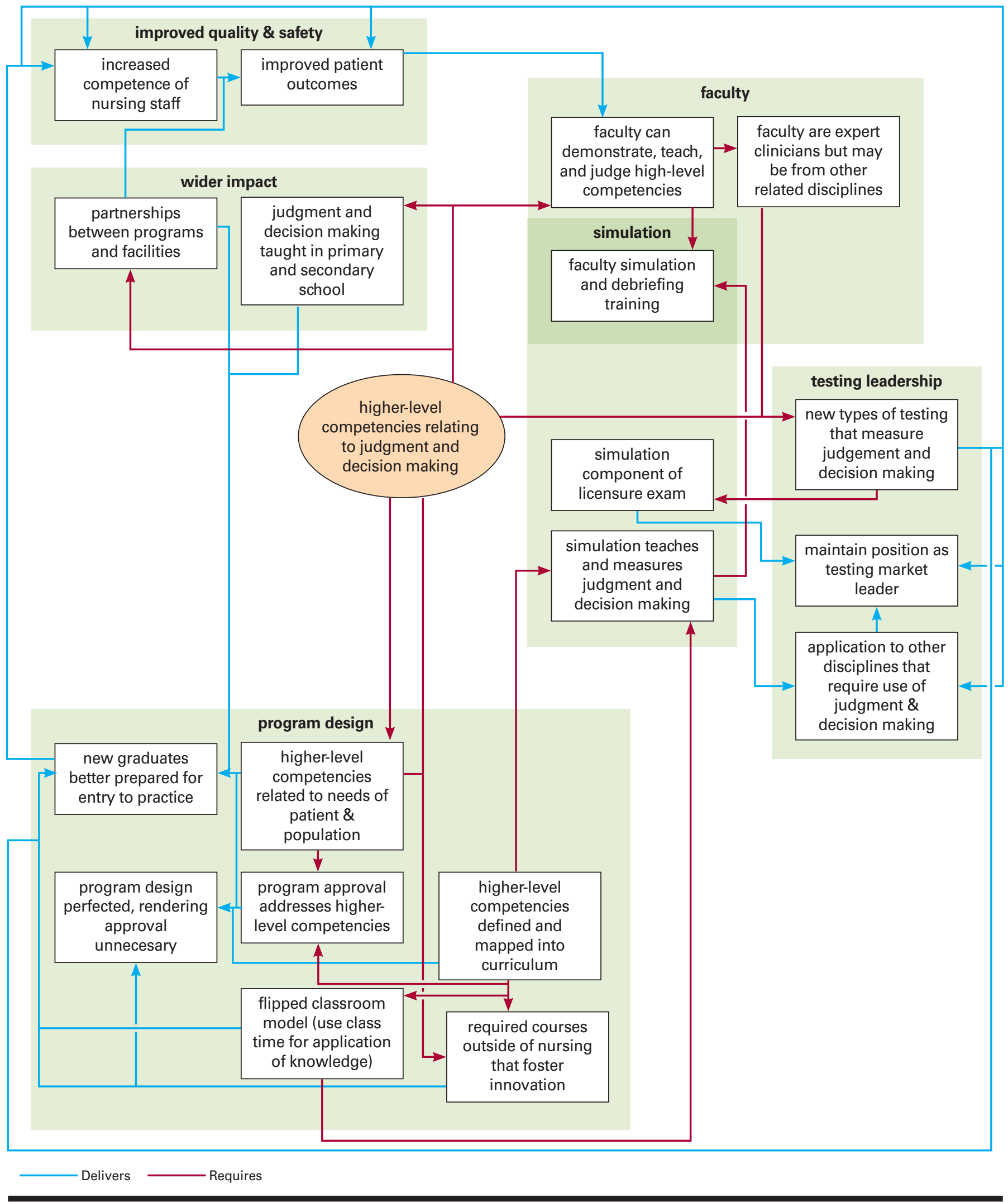




\section{CONCEPT MAP 15}

\section{Education >Curriculum Content > Global Calibration and Harmonization of Content}

This concept map explores the curriculum content theme in relation to education and its emergent trend, global calibration and harmonizing content.

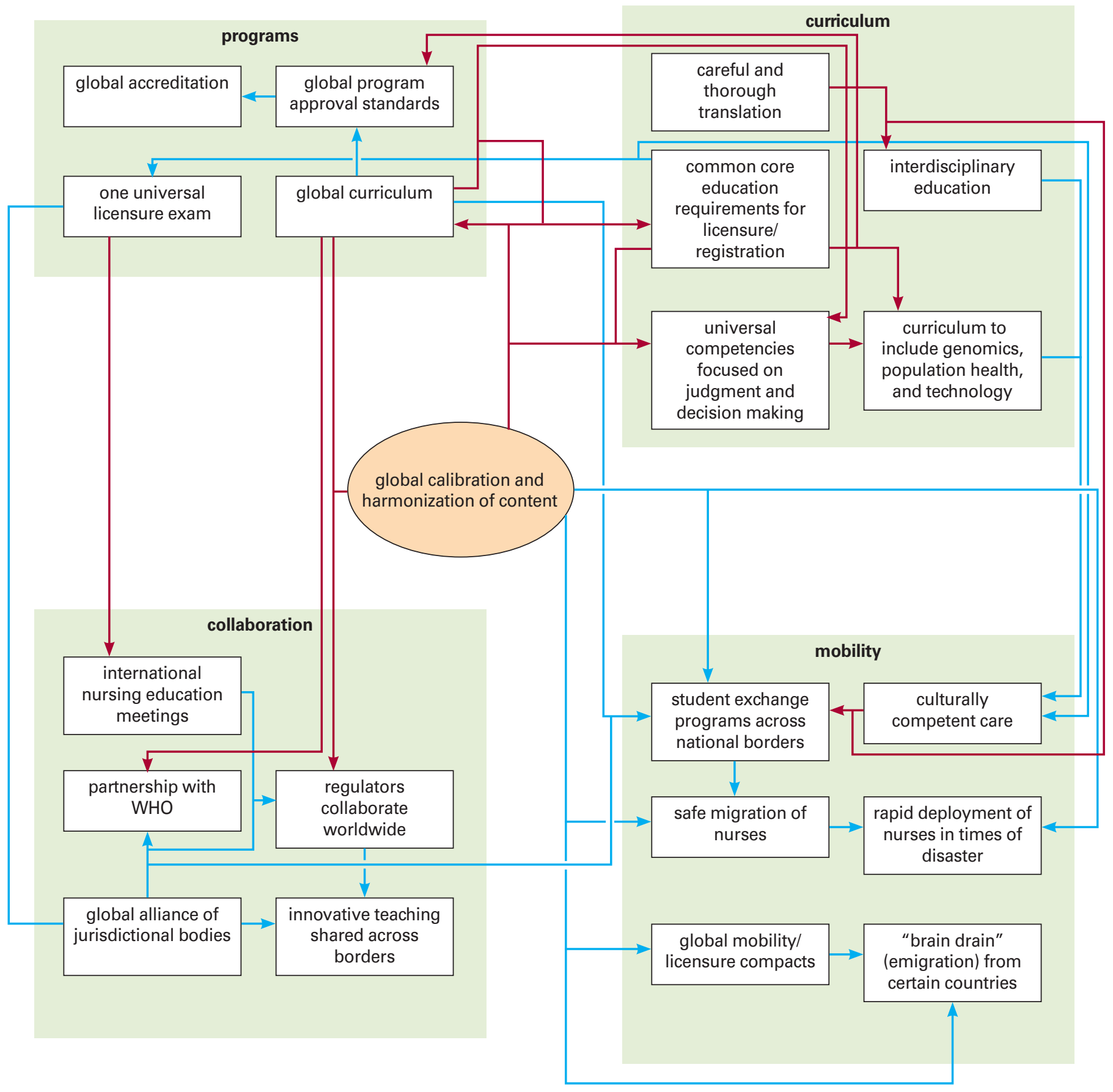




\section{CONCEPT MAP 16}

\section{Education >Accreditation of Institutions and Programs > Streamlined Capture for Multiple Use}

This concept map explores the accreditation of institutions and programs theme and it emergent trend, streamlined capture for multiple use.

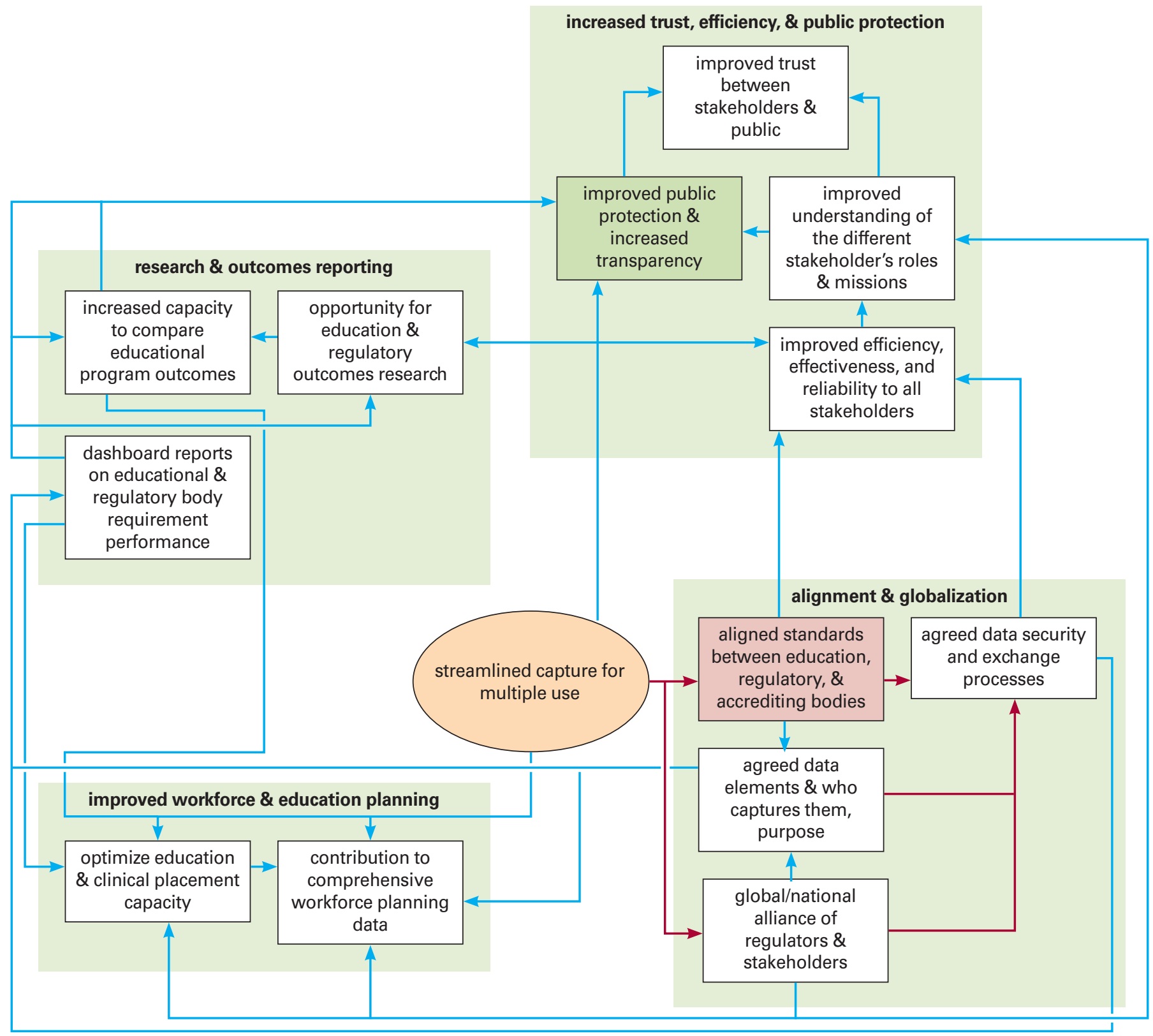




\section{CONCEPT MAP 17}

\section{Education >Learning $>$ Continuing and Maintaining Competence}

This concept map explores the learning theme in relation to education and its emergent trend, continuing and maintaining competence.

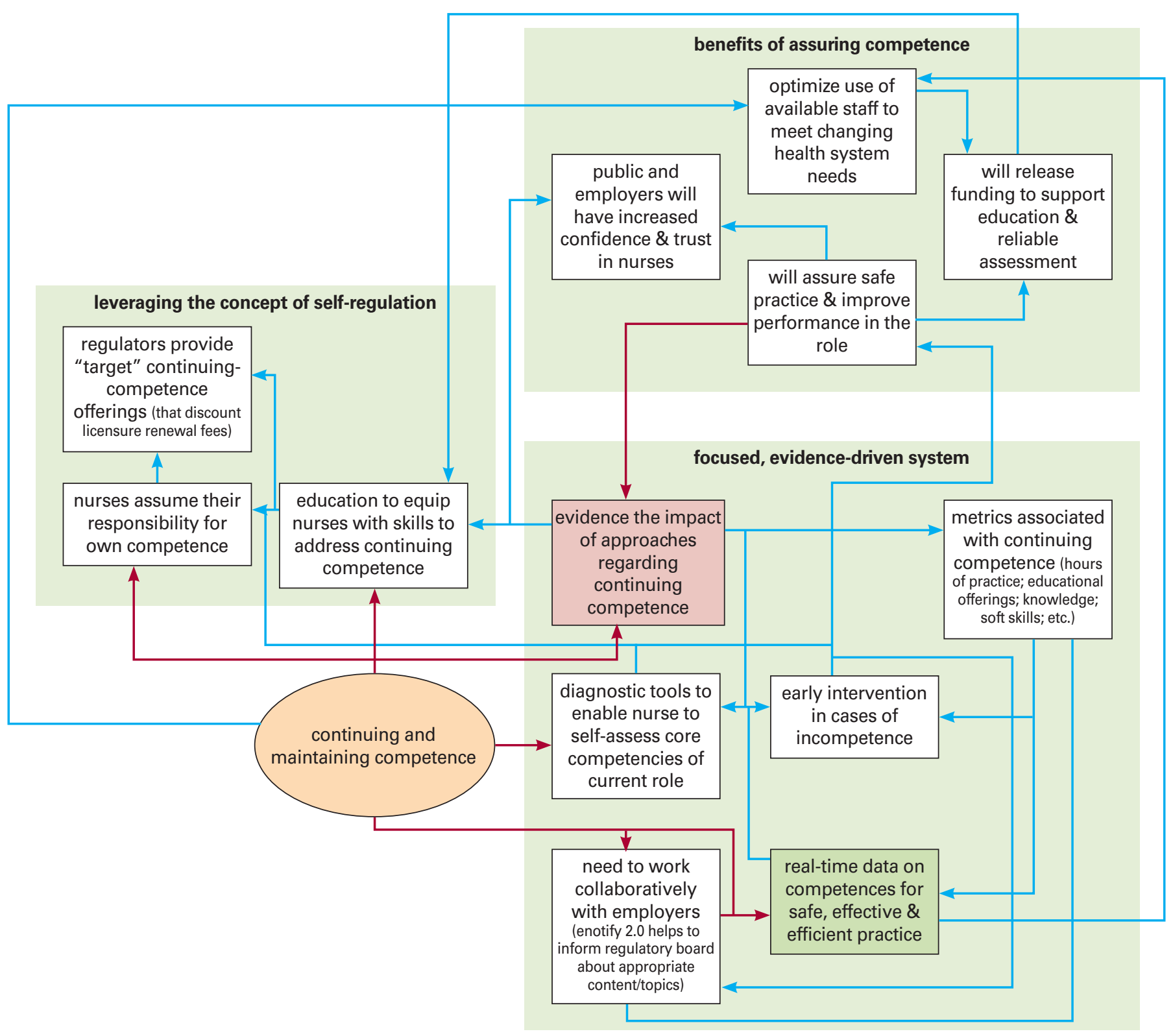




\section{CONCEPT MAP 18}

\section{Education >Pedagogy > Adult Learning and Blended Simulation, Gaming, and Practice}

This concept map explores the pedagogy theme in relation to education and its emergent trends, adult learning and blended simulation, gaming, and practice.

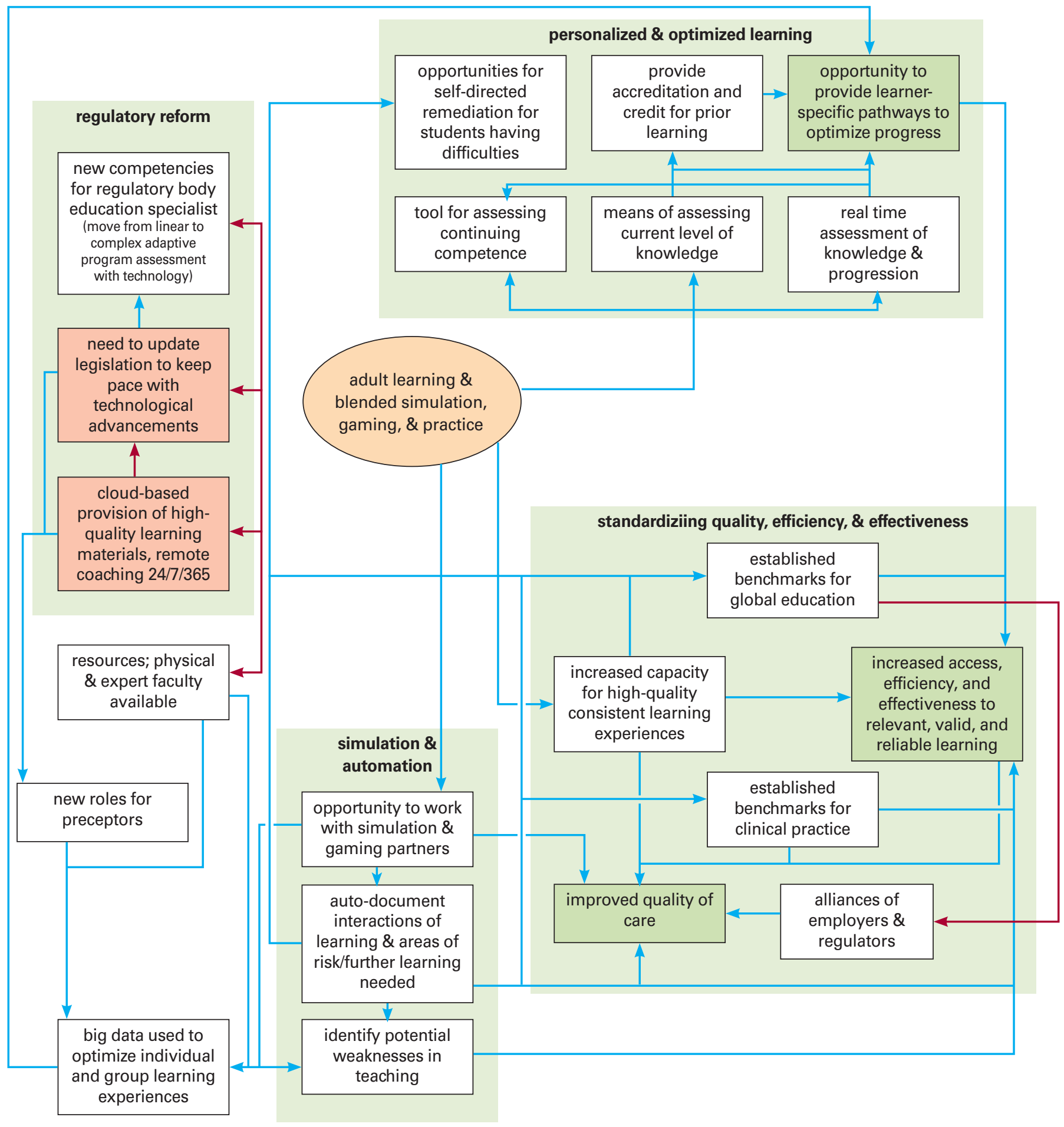




\section{CONCEPT MAP 19}

\section{Fitness for Practice > Fit Person >Ongoing Process with Criminal Background Checks and Rapback}

This concept map explores the fit person theme in relation to Fitness for practice and its emergent trend, Ongoing process with criminal background checks (CBCs) and rapback.

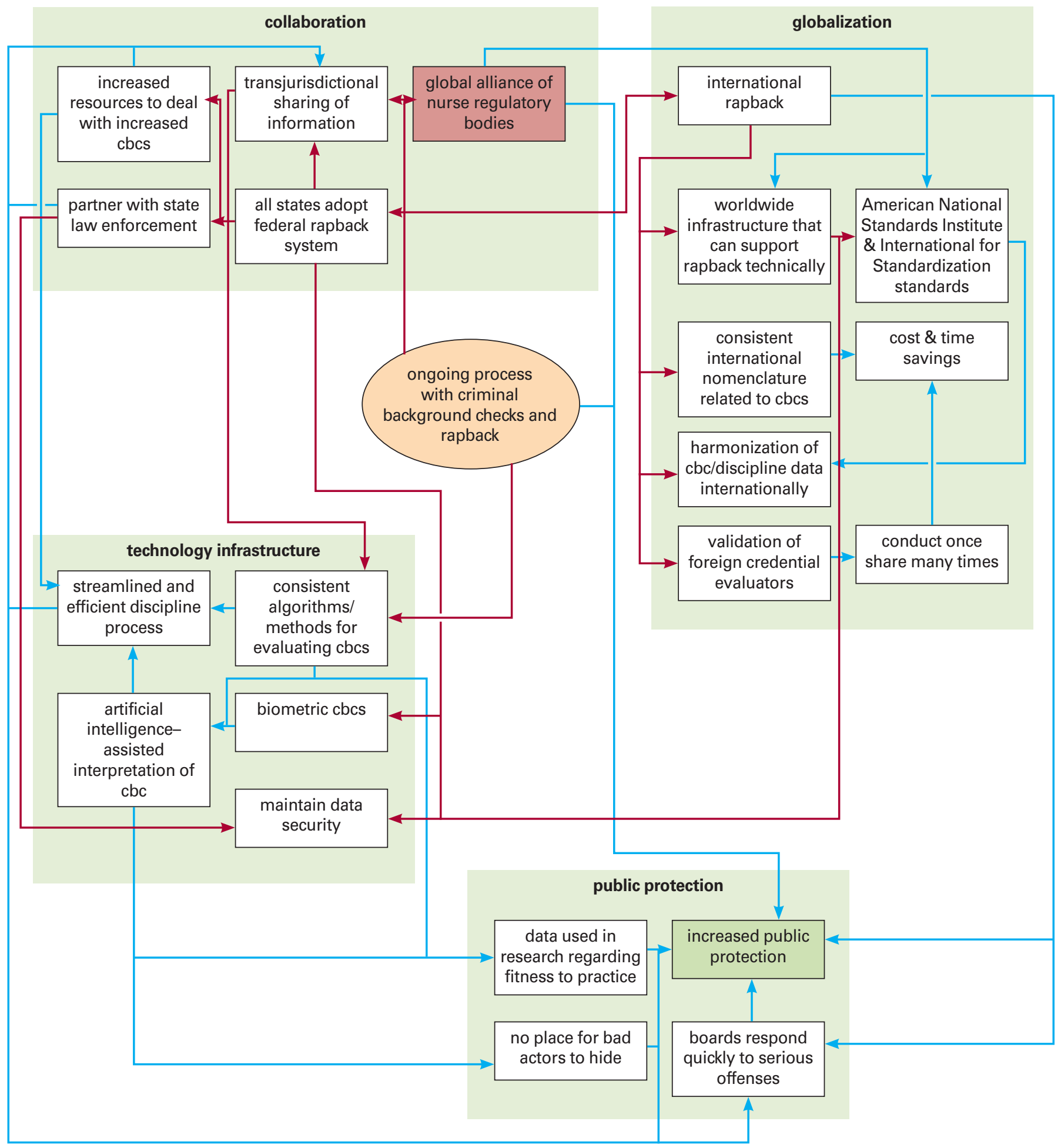




\section{CONCEPT MAP 20}

\section{Fitness for Practice > Dealing with Complaints > Clear Separation of Investigation, Judgment, and Outcome}

This concept map explores the dealing with complaints theme in relation to fitness for practice and its emergent trend, clear separation of investigations, judgments, and outcomes.

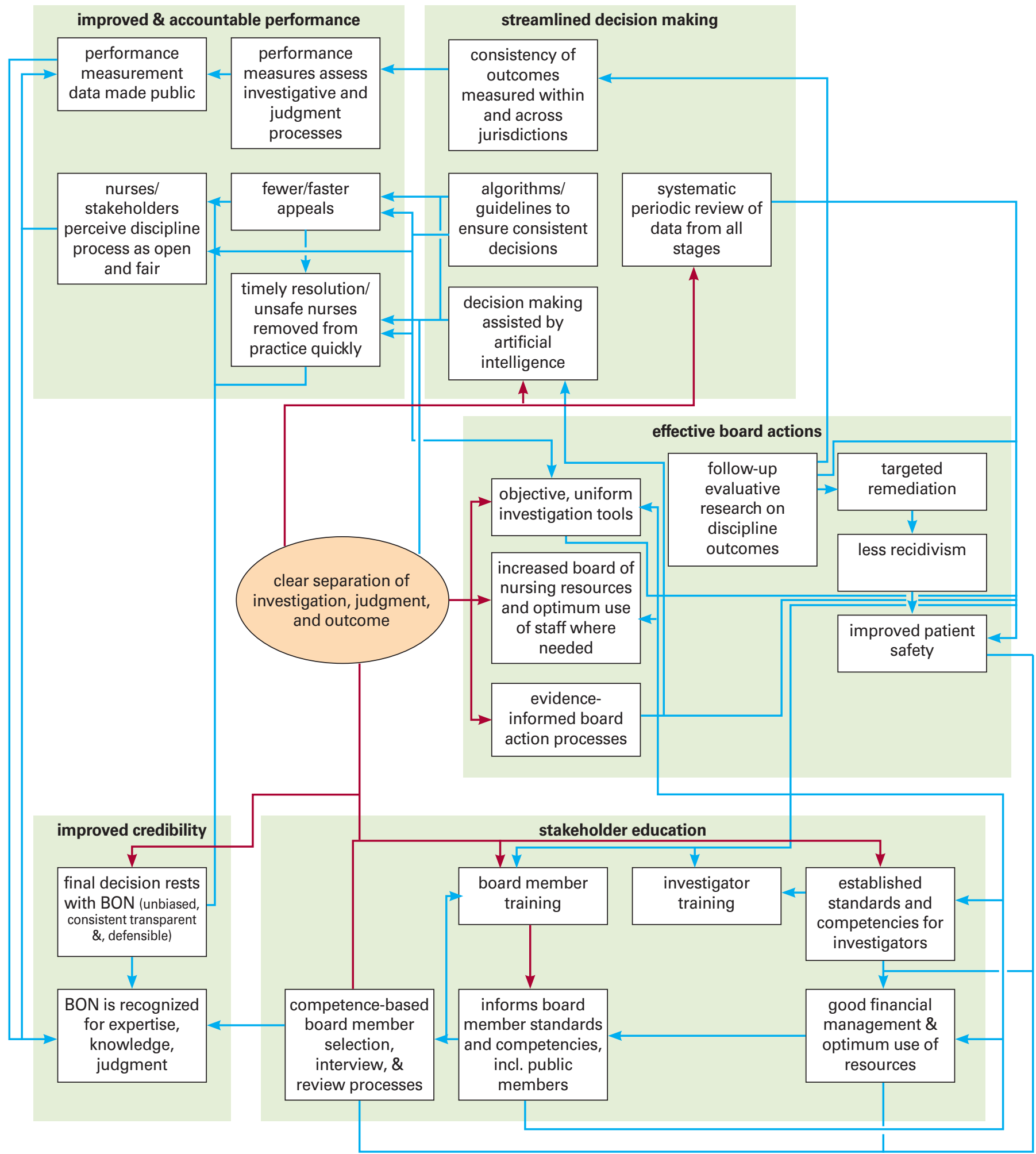

Delivers Requires 


\section{CONCEPT MAP 21}

\section{Fitness for Practice > Conduct Sanctions > Risk-Based Response and Wider Range of Sanctions}

This concept map explores the conduct sanctions theme in relation to fitness for practice and its emergent trend, risk-based response and wider range of sanctions.

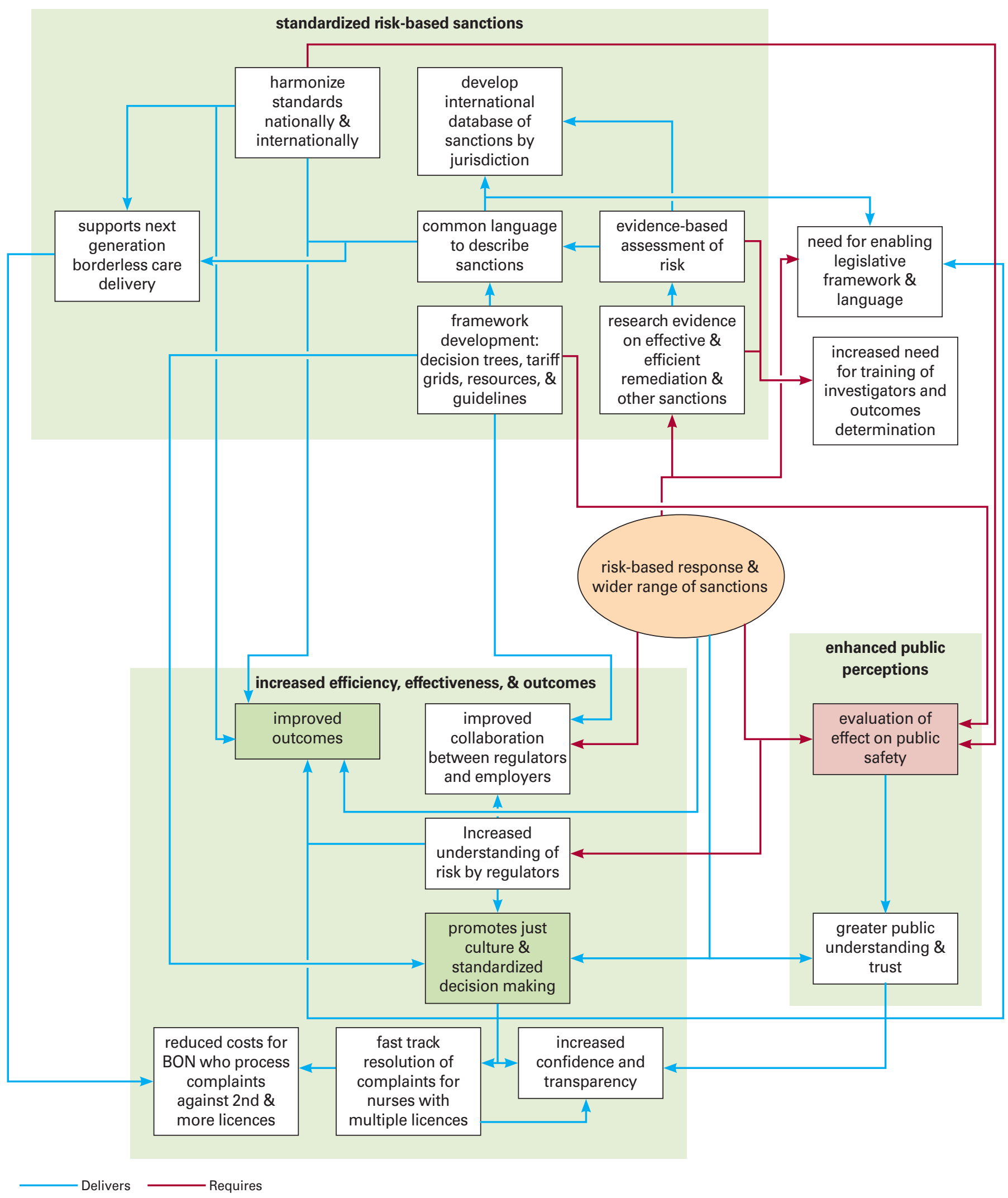




\section{CONCEPT MAP 22}

\section{Fitness for Practice > Entry to Practice > Application of Knowledge With Judgment and Decision Making}

This concept map explores the entry to practice theme in relation to fitness for practice and its emergent trend, application of knowledge with judgment and decision making.

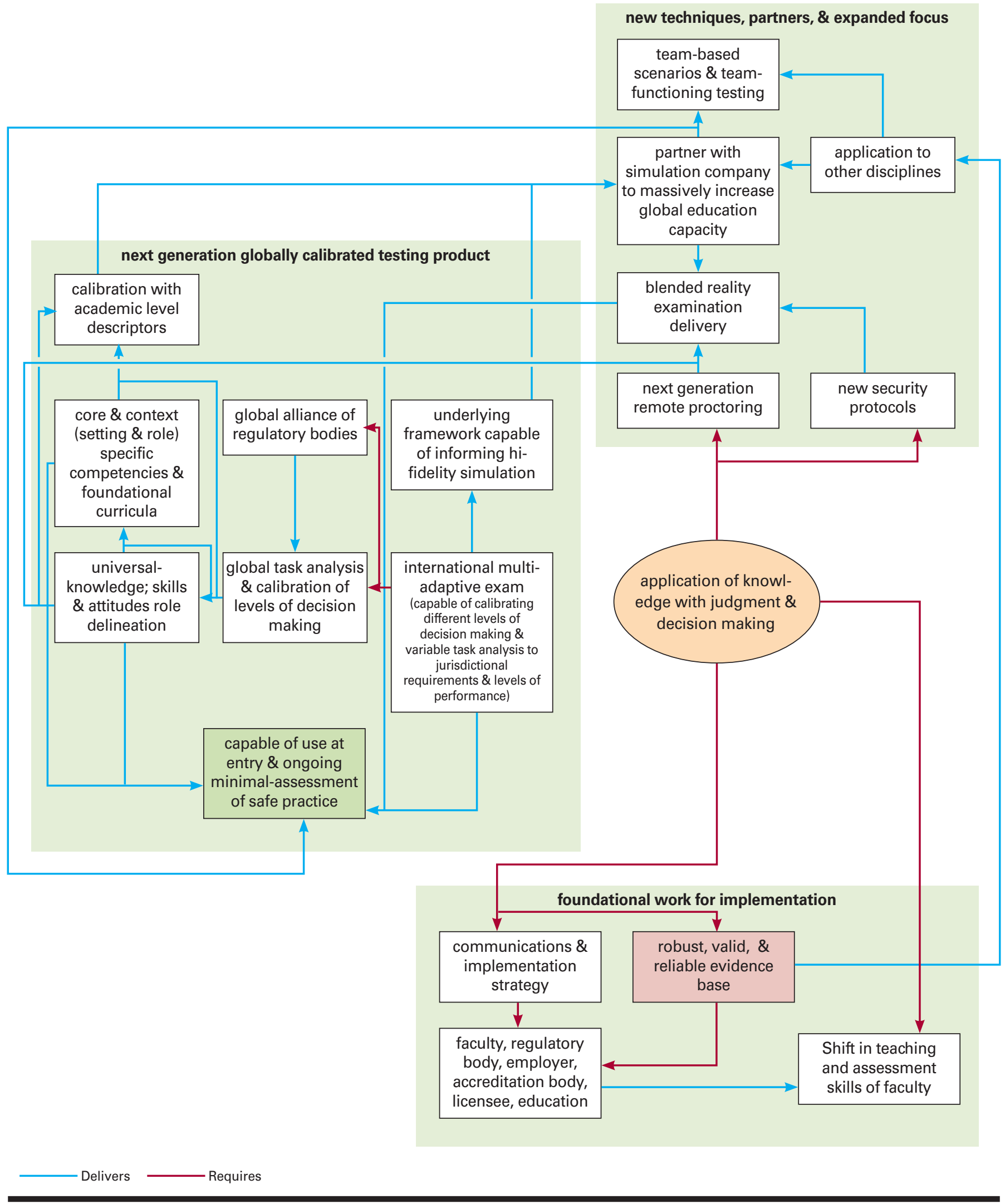




\section{CONCEPT MAP 23}

Technology and Information > Data Production and Storage > Cloud-Based Document Storage; Tranjurisdictional Interoperability and Dynamic Search Capability

This concept map explores the data production and storage theme in relation to technology and information and its emergent trend, cloud-based document storage; tranjurisdictional interoperability and dynamic search capability.

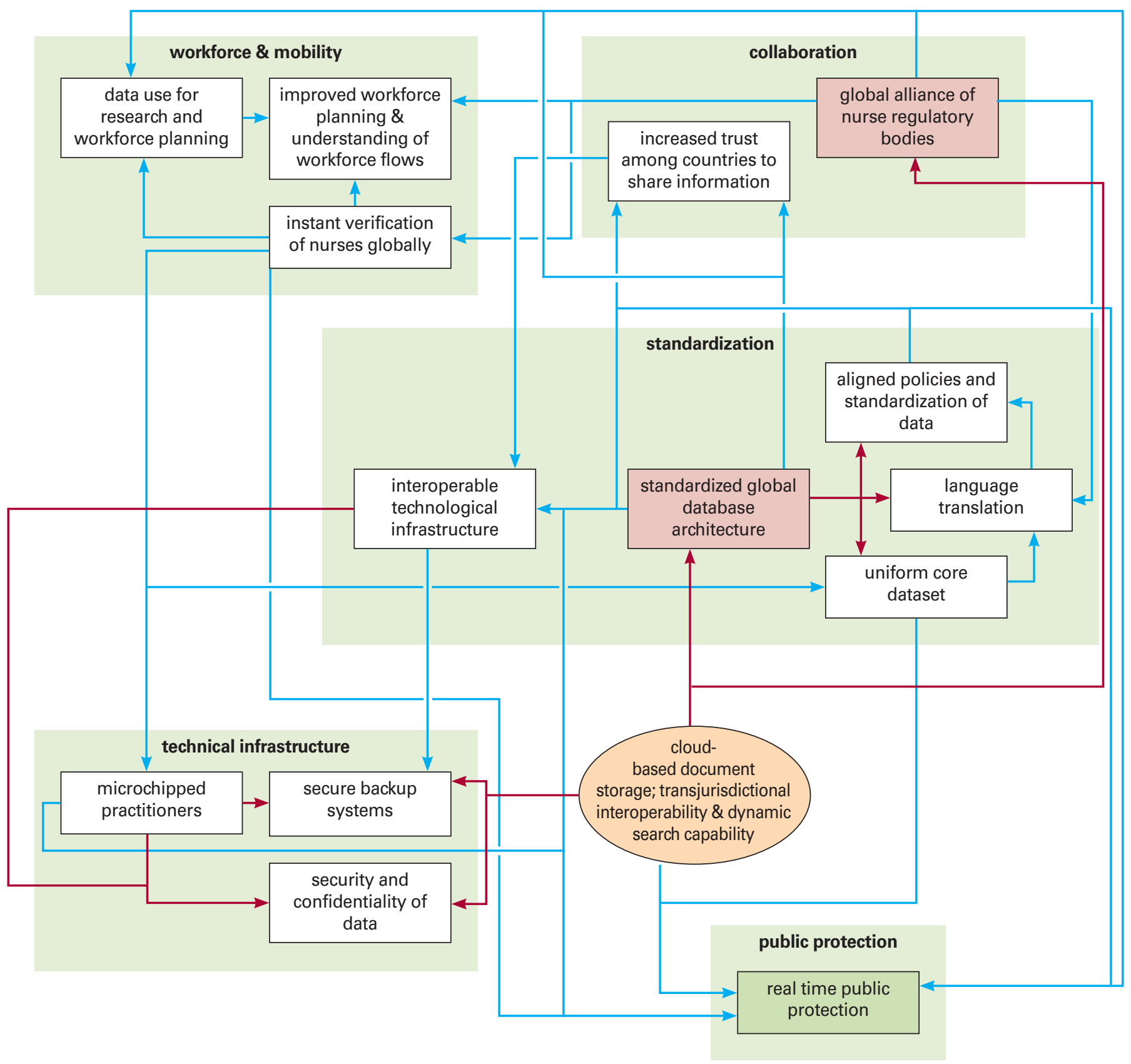




\section{CONCEPT MAP 24}

Technology and Information > Data Access > Real-Time Updates and Multiplatform Access

This concept map explores the data access theme in relation to technology and information and its emergent trend, real-time updates, and multiplatform access.

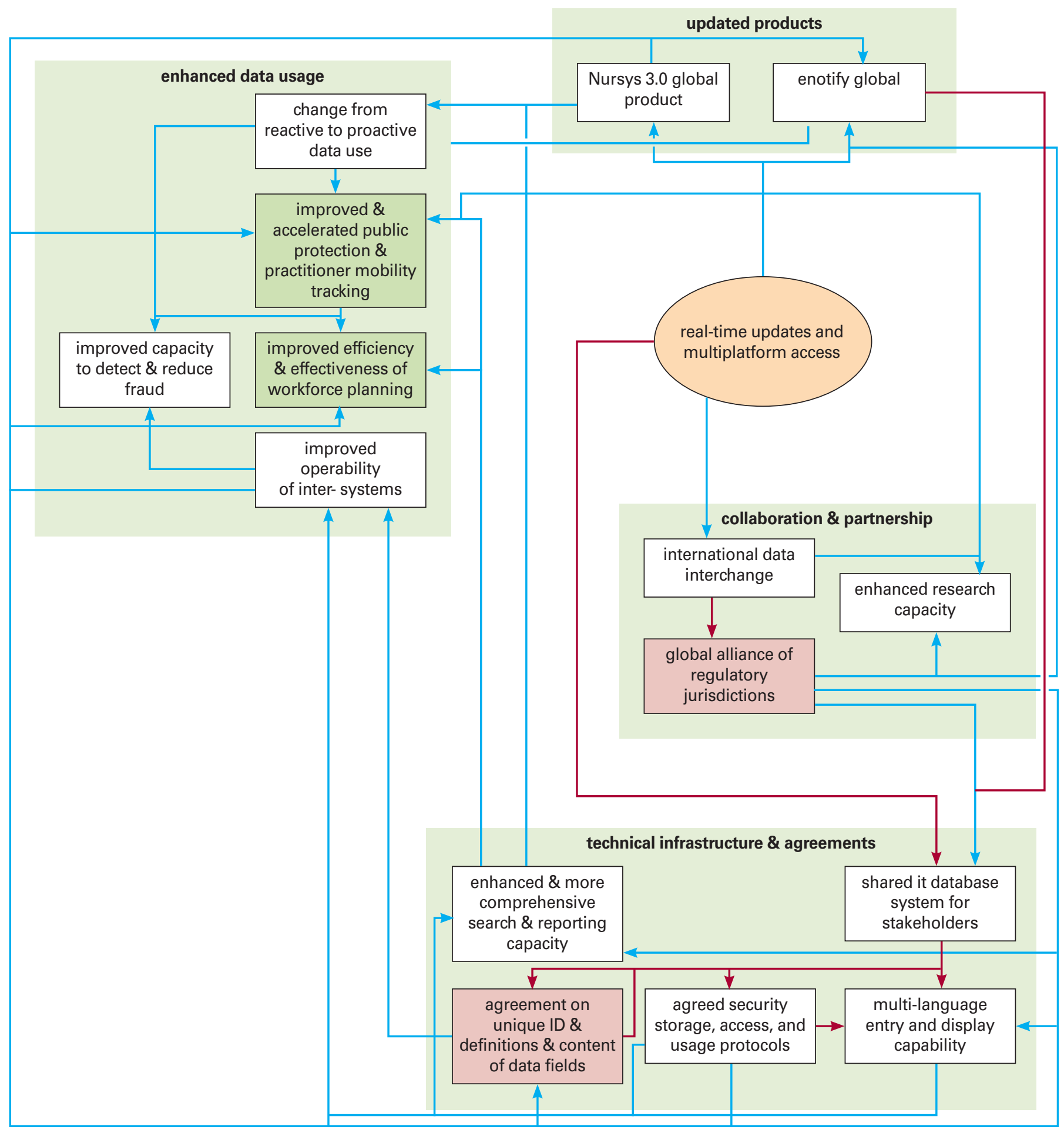




\section{CONCEPT MAP 25}

\section{Technology and Information > Relicensure > Smart Phone Completion Platforms With Digital Payment}

This concept map explores the relicensure theme in relation to technology and information and its emergent trend, smart phone completion with digital payment.

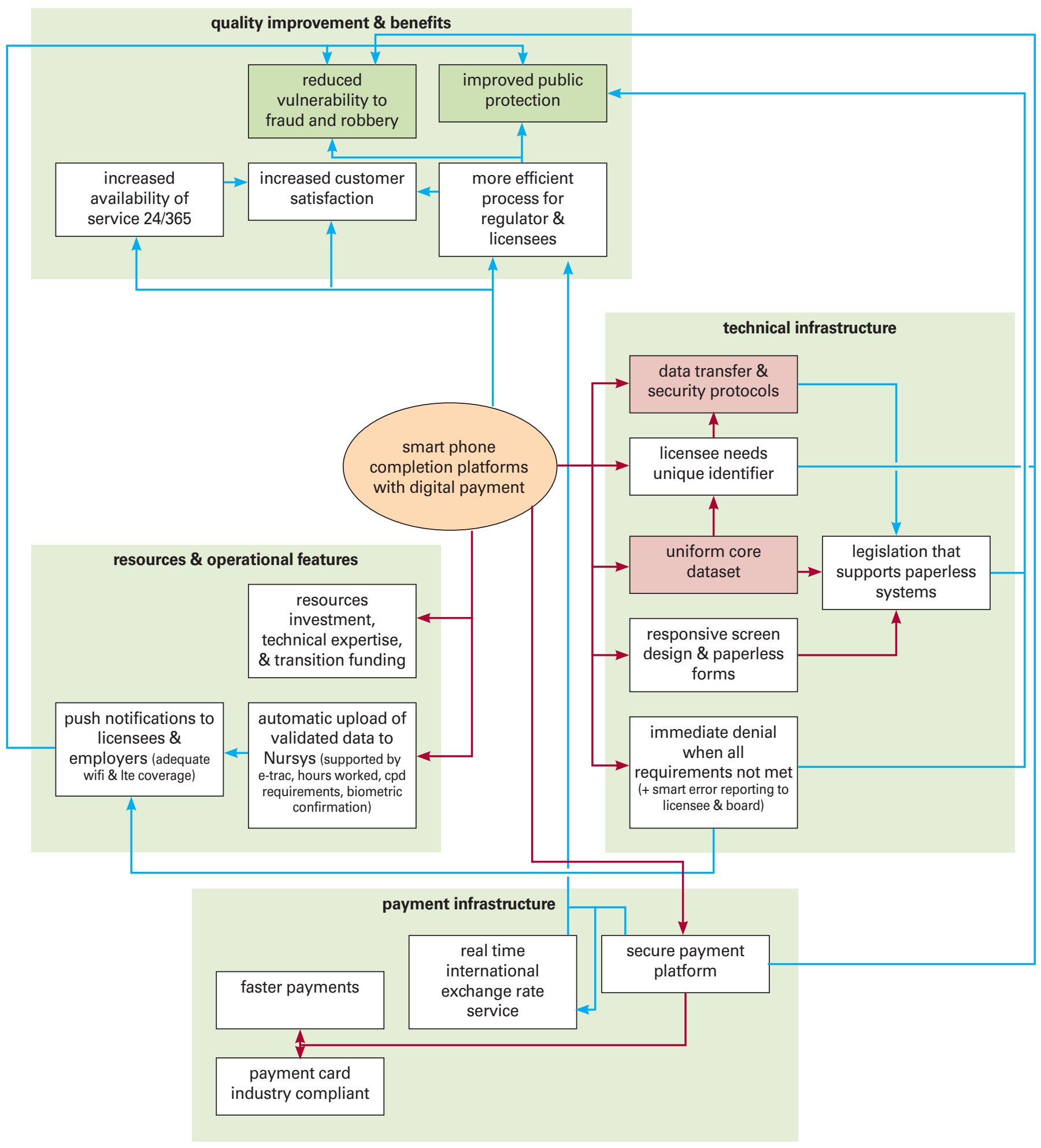

